Espacio y Desarrollo $\mathrm{N}^{\circ} 34,2019$, pp. 5-32 (ISSN 1016-9148)
https://doi.org/10.18800/espacioydesarrollo.201902.001

\title{
EVALUACIÓN Y MEDICIÓN DE LA EXPANSIÓN TERRITORIAL DE LA MINERÍA informal en la cuenca alta del Ramis, Puno, Perú, usando IMÁGENES SATELITALES
}

\author{
Ulises Francisco Giraldo Malca ${ }^{1}$ \\ https://orcid.org/0000-0002-8559-018X \\ Universidad Científica del Sur \\ Universidad Privada del Norte \\ ugiraldo@conecodes.com \\ Pedro Gonzalo Vasquez Ruesta \\ https://orcid.org/ 0000-0002-5695-751X \\ Universidad Nacional Agraria La Molina \\ cdc@lamolina.edu.pe
}

Fecha de recepción 16/04/2020

Fecha de aceptación 30/06/2020

\section{RESUMeN}

La presente investigación aborda la problemática ambiental que genera la explotación de oro de la minería informal en tres sectores de la cuenca alta del río Ramis (CARR), la cual constituye una de las actividades económicas más impactantes al medio ambiente y a la sociedad en el Perú. A pesar de existir normas específicas orientadas a su formalización y regulación, sus efectos negativos se han expandido e incrementado considerablemente en los últimos doce ańos. Precisamente, las tecnologías de teledetección constituyen herramientas eficientes, que pueden ser de muy bajo costo, útiles para evaluar y analizar la problemática ambiental de un área tan extensa como el ámbito de interés (perteneciente a la hoya hidrográfica del lago Titicaca), de modo que se logró ver la evolución que ha tenido la minería aurífera en esta zona mediante la cuantificación de la superficie que presentó cambios en el uso del suelo para el periodo comprendido entre 1984 y 2015, usando imágenes de satélite multiespectral Landsat.

1 Docente de la Universidad Científica del Sur y de la Universidad Privada del Norte.

2 Profesor principal de la Universidad Nacional Agraria La Molina (UNALM), director del Centro de Datos para la Conservación (CDC-UNALM). 
Los resultados del análisis de veintiséis imágenes satelitales diferentes, para detectar las superficies que tuvieron un cambio de uso de suelos, se comparan cronológicamente con la ocurrencia de hechos sociales, políticos y económicos, como la cotización internacional diaria del oro, manifestaciones del conflicto socio ambiental o acciones de intervención del gobierno, factores que influyeron en la expansión territorial o estancamiento de las actividades de minería informal en la zona, así como la eficacia que tuvo las acciones tomadas por parte de las autoridades competentes para su control o mitigación.

Palabras clave: minería informal, teledetección, sistemas de información geográfica, cambio de uso de suelos, conflicto socio ambiental.

\section{Evaluation and Measurement of the Territorial Expansion of Informal Mining in the Ramis High Basin, Puno, Perú Using Satellite Images}

\section{Abstract}

The following research is about the environmental problems who produce the gold exploitation of informal mining in three sectors of the Ramis River High Basin (CARR, due to its name in Spanish), which is one of the most impacting economic activities in the environment and society that is currently in Peru. In spite of the existence of specific norms oriented to their formalization and regulation, their negative effects have expanded and increased considerably in the last 12 years. Precisely, remote sensing technologies are very efficient low-cost tools to evaluate and analyze the environmental issues of the area of interest (which belongs to the hydrographic basin of the Titicaca Lake), being able to see the evolution that gold mining had in this area by quantifying the area that showed changes in land use for the period between 1984 and 2015, using Landsat multispectral satellite images.

The results of the digital analysis of satellite images of 26 different years for detect the surfaces who had a change in land use, is compared chronologically with the occurrence of social, political and economic events such as the gold international daily price, socio-environmental conflict demonstrations or government intervention actions, factors that influenced the territorial expansion or stagnation of informal mining activities in the area, as well as the effectiveness of the actions taken by the competent authorities for their control or mitigation.

Keywords: Informal mining, remote sensing, geographic information systems, land use change, socio-environmental conflict. 


\section{INTRODUCCIón}

La minería es reconocida como una de las actividades económicas más importante para el Perú como lo dijo textualmente el El Mercurio Peruano en una publicación de 1791 «[...] el principal objeto de este papel periódico [...] es hacer conocido al país que habitamos [...] La minería es el principal, y tal vez, el único manantial de riqueza del Perú». Desde la época colonial, fue la base de la economía, sobre todo por la extracción de metales en todo el ámbito andino. Sin embargo, a pesar que en los últimos cincuenta años la minería es la actividad exportadora más importante del país (Glave \& Kuramoto, 2000), con un 55\% de la balanza comercial de las exportaciones totales —US\$ 18832 millones- (Ministerio de Energía y Minas, 2016), su reducido encadenamiento productivo e intensidad de mano de obra representa apenas entre 4 a 6\% del PBI —que según El Comercio del 15/06/2015 se elevó al 11\%— (Vargas, 2015) — y el 1,2\% del empleo. Ello puede generar problemas con la población local que espera obtener mayores beneficios como empleo y participación en la explotación minera, viendo con desagrado la presencia de foráneos (Glave \& Kuramoto, 2000), sin mencionar los impactos ambientales que genera la actividad —alteración del paisaje y cambio de uso de suelos - y la presencia de pasivos ambientales producidos en el pasado; todo ello, junto al notable incremento del precio internacional del oro en los últimos doce ańos, favorecieron la aparición de pequeños operarios mineros y mineros artesanales, siendo informales la gran mayoría de ellos.

En la cuenca del río Ramis se lleva a cabo la explotación aurífera informal en las cabeceras de la subcuenca del Alto Azángaro, la cual presenta un conflicto socio ambiental implícito entre mineros de la cuenca alta y poblaciones asentadas aguas abajo, ya que afectados y contaminantes aparentemente no son conscientes de las reales dimensiones del problema, o simplemente lo obvian en perjuicio de los afectados. Más adelante, cuando los efectos negativos sean evidentes, el conflicto podría estallar con mayor intensidad y con consecuencias mucho más serias, por lo que es necesario mostrar las dimensiones que tiene el impacto de la minería informal y demandar la atención temprana por parte de las entidades competentes en pos de evitar futuras confrontaciones.

La minería de oro informal en yacimientos aluviales — como los presentes en el ámbito de estudio-, tiene un fuerte impacto en el paisaje al eliminar por completo la vegetación y el suelo ${ }^{3}$ ubicados sobre el yacimiento a explotar. Pero, a diferencia de la minería formal, es realizada por un gran número de operadores distintos, que no tienen límites definidos para la expansión de sus actividades. Esta no tiene la necesidad de cumplir con estándares de calidad ambiental (ECA), límite máximo permisible

\footnotetext{
3 Suelo: capa superficial de la litosfera con capacidad productiva.
} 
(LMP) o norma laboral alguna, al no estar sujeta a acciones de fiscalización por parte de entidades reguladoras.

Hay mucho por hacer para mejorar la situación en la zona. En ese sentido, podemos afirmar que, a la fecha, contamos con tecnologías y herramientas que nos permitirían cubrir vacíos de información que aporten a una adecuada gestión de sitios como este. Los sensores remotos — los sistemas de información geográfica (SIG) - y la disposición de galerías históricas de imágenes satelitales, nos posibilitan revisar cómo fue la evolución de esta actividad en las últimas tres décadas. Con ello, se puede detectar los periodos en los que presentó su mayor auge y aquellos en los que tuvo una reducción en su crecimiento, los mismos que finalmente pueden ser relacionados con variables económicas, sociales o políticas de coyuntura que hayan afectado su desarrollo.

\section{2. ÁREA DE ESTUDIO}

La cuenca del río Ramis forma parte de la hoya hidrográfica del lago Titicaca, siendo la de mayor aporte hídrico y extensión con un área total de $15139.88 \mathrm{~km}^{2}$. Está conformada por las cuencas de los ríos Pucará y Azángaro que nacen en las cumbres del nudo de Vilcanota y los nevados de la cordillera de Carabaya respectivamente; además de una intercuenca correspondiente a la cuenca baja del río Ramis. En el presente análisis, nos enfocamos, principalmente, en la cuenca del río Azángaro y la intercuenca del río Ramis, ámbito afectado de modo directo por los impactos ambientales generados por la minería informal en su cuenca alta.

Su relevancia en el departamento de Puno se debe a que provee importantes recursos naturales y servicios ambientales, claves para el sostenimiento de sus habitantes y la economía regional.

Tabla 1. División física de la cuenca del río Ramis

\begin{tabular}{lc}
\hline \multicolumn{1}{c}{ Nombre } & Extensión \\
\hline Cuenca del río Azángaro & $8885,77 \mathrm{~km}^{2}$ \\
Cuenca del río Pucará & $5474,27 \mathrm{~km}^{2}$ \\
Intercuenca del río Ramis & $779,84 \mathrm{~km}^{2}$ \\
\hline
\end{tabular}

Fuente: Giraldo (2017).

En términos biológicos, es el sector con mayor biodiversidad de todo el altiplano puneño porque alberga hasta siete zonas de vida que cubren desde las riberas del lago Titicaca (3810 m s. n. m.) hasta los glaciares de la Rinconada (5700 m s. n. m.), y en cuyo perfil topográfico cuenta con todos los pisos altitudinales que pueden presentarse 
en la hoya hidrográfica del Titicaca. El principal símbolo de esta riqueza viene a ser la Reserva Nacional del Titicaca, cuya sección norte se encuentra precisamente en la desembocadura del río Ramis. Esta es una zona de alta productividad, que forma un refugio natural para gran diversidad de aves nativas y migratorias; fue declarada en 1978 área natural protegida, y en el año 1997 (como parte del lago) declarada como sitio Ramsar, por ser un lugar clave de descanso de aves migratorias que se desplazan por varios países a lo largo de todo el continente americano.

Los ecosistemas que alberga son típicos de zonas montańosas tropicales, con presencia de microhábitats en los que se tiene endemismos de flora y fauna silvestre de distribución restringida y que son particularmente susceptibles a la alteración de su entorno por la actividad antrópica. Dentro de la cuenca podemos distinguir hasta cinco zonas de vida según el mapa ecológico elaborado por la ONERN en 1976 que utiliza el sistema de clasificación de Holdridge:

a) Bosque húmedo - Montano subtropical (bh-MS)

b) Páramo muy húmedo - Subalpino subtropical (pmh-SaS)

c) Páramo pluvial - Subalpino subtropical (pp-SaS)

d) Tundra pluvial - Alpino Subtropical (tp-AS)

e) Nival Subtropical (NS)

Su riqueza biológica se debe principalmente a la ubicación de la cuenca — próxima a la cordillera oriental—, ya que parte de la humedad proveniente de la Amazonía logra sobrepasar las cumbres de la cordillera y se precipita en su territorio, lo que proporciona un mayor volumen de agua a sus ecosistemas y una mayor red hidrográfica, en comparación con las otras cuencas del Altiplano. Las precipitaciones se concentran en la época húmeda — de diciembre a abril—. El resto del año los escurrimientos superficiales llegan a valores mínimos. El caudal promedio del río Ramis es de $76 \mathrm{~m}^{3} / \mathrm{seg}$, lo cual lo constituye como el principal aportante al lago Titicaca y regulador hídrico de la cuenca (Ogateirn-Inrena, 2006)

Ello da mejores condiciones a sus pobladores para su mantenimiento y desarrollo de actividades económicas como la agricultura, la ganadería y la minería. El tener ecosistemas más productivos, como praderas con mejores pastos y mayor capacidad de carga, permite a las provincias de Azángaro y Melgar ser consideradas dentro de las principales zonas productoras de leche y carne a nivel nacional.

Asimismo, bajo sus suelos y en las cumbres de la cordillera de Carabaya, subyace una riqueza mineral importante que, justamente, le da un potencial minero privilegiado por la presencia de yacimiento de oro, plata, cobre, plomo y zinc, que ha atraído la inversión de la gran minería representada por San Rafael (Minsur), Arasi (Aruntani S.A.C) y Las Águilas (Ciemsa), pero también despertó el interés de la población local (principal promotora de la minería artesanal) e inversionistas informales. La riqueza natural que ostenta la cuenca del río Ramis nos presenta diferentes potencialidades en 
un mismo territorio, que hace de su gestión una tarea compleja y difícil por el gran número de actores presentes y cuyos intereses, a veces, no son compatibles pudiendo llegar a ser contrapuestos en algunos casos.

Figura 1. Cuenca del río Ramis y su división física

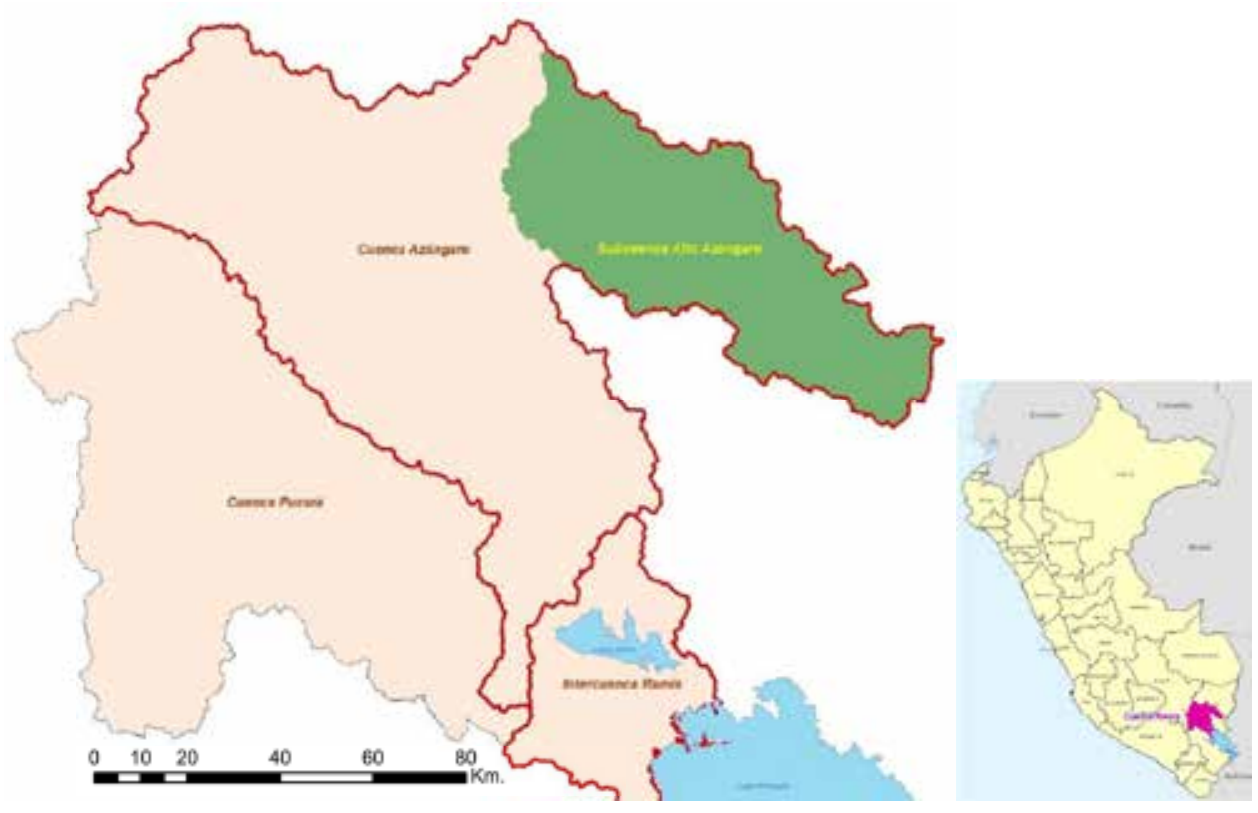

Fuente: Giraldo (2017).

Según el Inrena, la cuenca del río Ramis cuenta con tres segmentos claramente diferenciados:

- Cuenca alta: unidad cordillerana, con altitudes superiores a $4200 \mathrm{~m} \mathrm{~s}$. n. m., que presentan formaciones ecológicas de Maleza desértica subalpina y Tundra húmeda alpina, parte de Páramo muy húmedo subalpino, Tundra pluvial alpina así como formaciones nivales; $y$ en donde se desarrolla casi de forma exclusiva la actividad de crianza de camélidos sudamericanos (alpacas y llamas) y actividades mineras (Ogateirn-Inrena, 2006)

- Cuenca media: unidad de laderas y áreas intermedias — que varía de 4000 a 4200 m s. n. m. - , que corresponden a las formaciones ecológicas de Páramo muy húmedo subalpino, Tundra pluvial alpina, Páramo húmedo subalpino, Páramo muy húmedo alpino, cuyas características favorecen, predominantemente, al desarrollo de la actividad pecuaria relacionada con la crianza de ovinos y camélidos sudamericanos (Ogateirn-Inrena, 2006). 
- Cuenca baja: unidad del altiplano que abarca desde los 3800 hasta los $4000 \mathrm{~m} \mathrm{s.} \mathrm{n.}$ $\mathrm{m}$. Presenta en su mayor parte una formación ecológica de Bosque húmedo montano y Estepa montana. En esta unidad se ubica la mayor parte de la población, ya que aquí se encuentran las ciudades más grandes: Achaya, Azángaro, Asillo, Progreso y San Antón. En ella se desarrolla, fundamentalmente, la actividad pecuaria (vacuna y ovina) gracias a la abundancia de pastos naturales, también se presenta en menor proporción actividad agrícola de cultivos altoandinos (Ogateirn-Inrena, 2006)

Figura 2. Segmentos de la cuenca del río Ramis

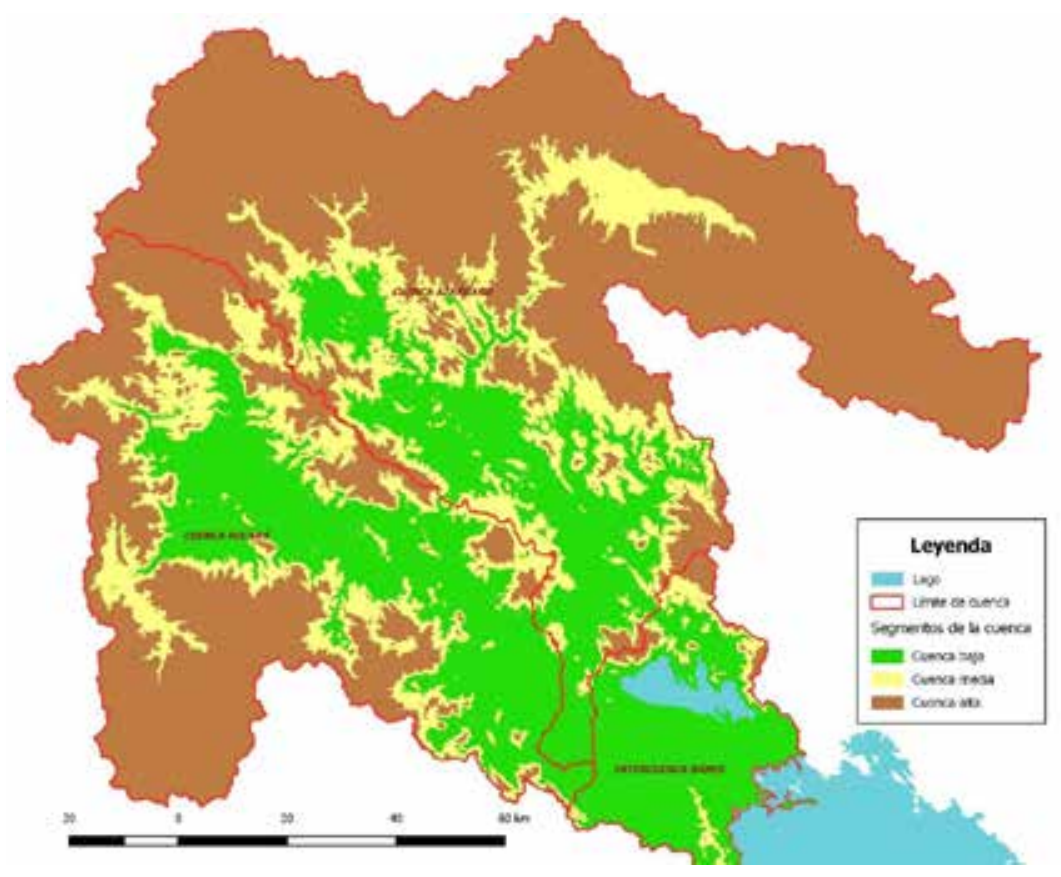

Dentro de la unidad cuenca baja se puede distinguir claramente el área circunlacustre que va desde los 3812 hasta los $3900 \mathrm{~m} \mathrm{~s}$. n. m., correspondiente a los terrenos ubicados en las cercanías a la ribera del lago Titicaca. Esta área se caracteriza por tener una alta densidad poblacional que desarrolla actividades agrícolas y pecuarias de mayor envergadura gracias a las mejores condiciones climáticas que tiene por la influencia termorreguladora del lago, a diferencia del resto del Altiplano en donde solo existen condiciones para la crianza extensiva de ganado y la agricultura de subsistencia (ONERN Corpuno, 1965). 
Figura 3. Ámbito de interés (Intercuenca Ramis y cuenca del río Azángaro)

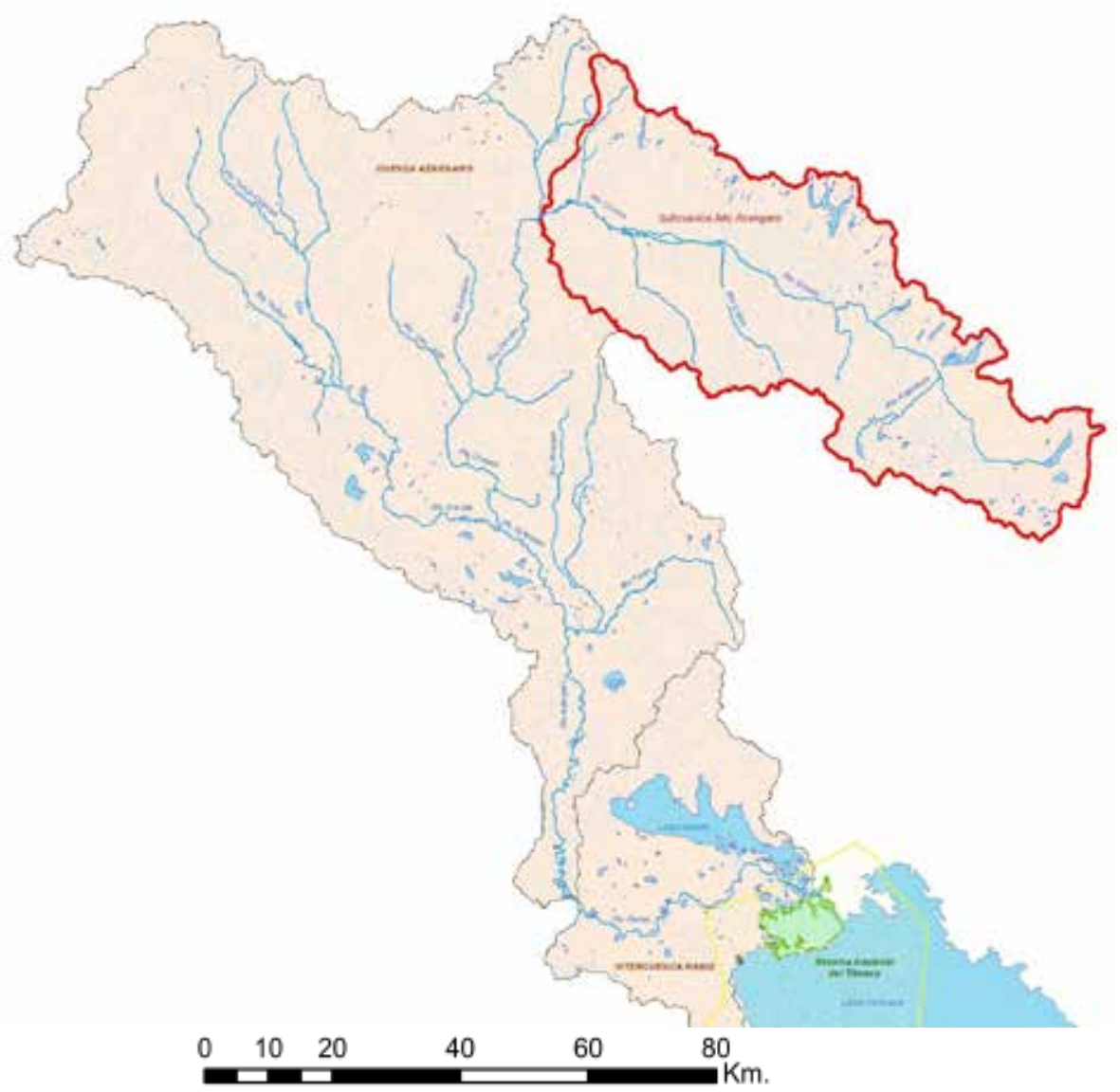

Fuente: Giraldo (2017).

De acuerdo al mapa nacional de capacidad de uso mayor de suelos que elaboró el Inrena el año 1992, se identificaron un total de ocho clases que muestran las potencialidades productivas que tiene su territorio, en los cuales predominan los usos ganaderos y de protección, lo cual restringe el ámbito con potencial agrícola a la cuenca baja y la circunlacustre. La capa arable de los suelos de la cuenca alta y media es muy delgada y está expuesta a procesos erosivos por las pendientes y los vientos que presenta, y tiene limitaciones para el desarrollo agrícola y ganadero, lo que muestra la fragilidad ambiental de la zona alta y su mayor susceptibilidad ante los impactos que genera las actividades antrópicas.

De acuerdo a lo identificado por el Ingemmet (Acosta, Rodríguez, Valencia y Flores, 2011), Puno presenta una gama de yacimientos auríferos: filones de origen hidrotermal, placeres formados por erosión del macizo de la cordillera Oriental o de 
Carabaya, yacimientos eluviales (morrenas), y yacimientos aluviales arrastrados hacia las partes bajas depositados lejos de su origen.

Dentro de los principales yacimientos filoneanos que se presentan dentro del ámbito de interés se encuentran los siguientes:

a) Ananea, yacimiento de tipo aluvial que presenta una forma diseminada. Se estima en reserva 580000 toneladas con una ley de $42 \mathrm{~g} / \mathrm{t}$ (gramos de oro por tonelada) (DREM Puno, 2005).

b) Guarnacabo, yacimiento formado por sedimentos Pleistocénicos y actuales de origen glacial, con contenido de oro nativo libre en cantos rodados y bloques de cuarzo aurífero de un volumen que supera los 100 millones de metros cúbicos, con leyes probadas de 0,350 gramos por metro cúbico (Olivari Ortega, 1992).

c) La Rinconada (Ana María), yacimiento filoniano que cuenta con 44 mantos y su reserva en mineral es de 2.24 millones de toneladas. La ley promedio es de $10 \mathrm{a}$ $20 \mathrm{~g} / \mathrm{t}$ (Cueva Yñigo, 1992), que reportan leyes hasta $800 \mathrm{~g} / \mathrm{t}$. (Acosta et al., 2011).

d) San Antonio de Poto se encuentra en los parajes de Pampa Blanca y Vizcachani, corresponde a placeres auríferos, donde el oro se encuentra en varias formas, como chispas, pepitas o diseminado, corresponden a formaciones morrénicas de acción glaciar típica y complejos fluvioglaciares (Acosta et al., 2011), las leyes promedio son de $0,29 \mathrm{~g} / \mathrm{m}^{3}$, cuyas reservas alcanzan los 168000000 de toneladas de material aluvial.

En la zona de Pampa Blanca, las concentraciones de oro son mayores que en Ananea, que alcanzan en la parte central hasta sesenta metros de grosor, con reservas mayores a los $400000000 \mathrm{~m}^{3}$, probablemente influenciada por su cercanía a la mina de oro vetiforme La Rinconada (Acosta et al., 2011).

\section{El Cambio de uso de suelos (CUS) en la cuenca alta del Ramis}

Las zonas mineras de Ananea y Cuyocuyo (cuenca alta del río Ramis) de modo natural tienen un paisaje de páramo altoandino (ver Figura 4), cubierto de una capa de vegetación herbácea de tamaño bajo cuya concentración varía de buena a dispersa. Estas praderas fueron aprovechadas a lo largo de la historia para el pastoreo de ovejas, llamas y alpacas, explotando su principal potencial productivo (ganadero), por lo cual la comunidad campesina de Ananea destaca por los buenos ejemplares de alpacas que tienen hasta la fecha. A pesar de que la explotación minera aurífera en la zona data de varios siglos atrás, hasta la década de 1950 no competía en el uso del territorio con la ganadería, ya que sus operaciones se concentraban únicamente en la Rinconada y Cerro Lunar (faldas del nevado Ananea). 
Figura 4. Pradera altoandina y Poblado de Ananea (al fondo) en la década de 1990

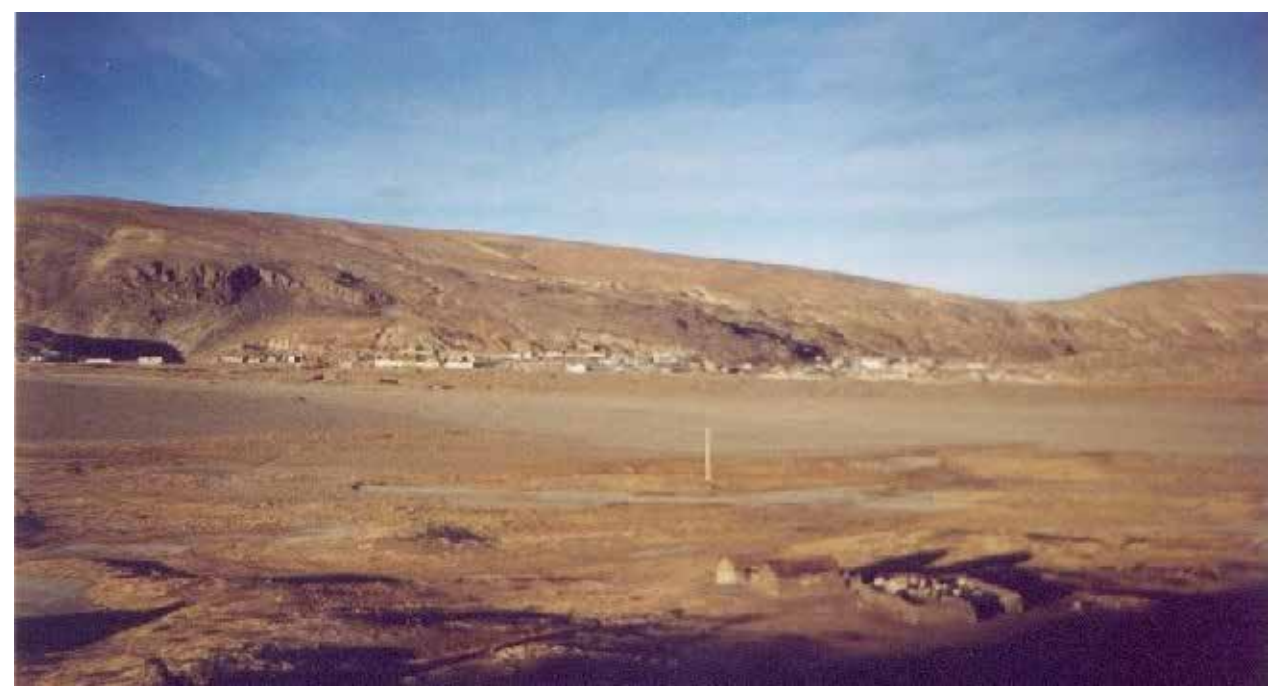

Fuente: http://esmiperu.blogspot.pe/2006/12/ananea-puno.html

Esta situación cambió a partir de la década de 1960, con el inicio de la explotación de placeres y morrenas auríferas en el sector de Pampa Blanca y que en años más recientes se extiende a los sectores de Ananea y Chaquiminas. Estas operaciones empezaron a alterar el paisaje de la zona debido al agresivo CUS, el cual se debe al método de explotación empleado en este tipo de yacimientos que consiste en remover totalmente la cobertura vegetal y los primeros horizontes del suelo (horizonte orgánico y horizonte A), lo cual dejaba al descubierto el material mineralizado de los horizontes B o C. Acto seguido, se dan las etapas de acarreo del mineral, traslado hasta los lugares donde será procesado (principalmente chutes), y finalmente disposición de residuos o relaves en los alrededores. Estas acciones generan la aparición de forados en el terreno, acumulación de desmontes, empozamientos de agua de forma desordenada y vertimiento de relave.

Todo el proceso descrito constituye el cambio en el uso del suelo (del pecuario al minero), el cual provoca una modificación radical en el paisaje. Este tipo de impacto es fácilmente identificable con herramientas de teledetección como imágenes satelitales o fotografías aéreas, gracias a las características que tienen (suelo desnudo, sin cobertura vegetal y con una alta concentración de pequeños cuerpos de agua dispersos de forma desordenada) que contrasta de forma clara con los ámbitos que no tiene mayor intervención antrópica como se muestra en las Figuras 6 y 7. 
Figura 5. Ciudad de Ananea, capital del distrito, y en sus alrededores área intervenida para la explotación minera aurífera informal, 2013

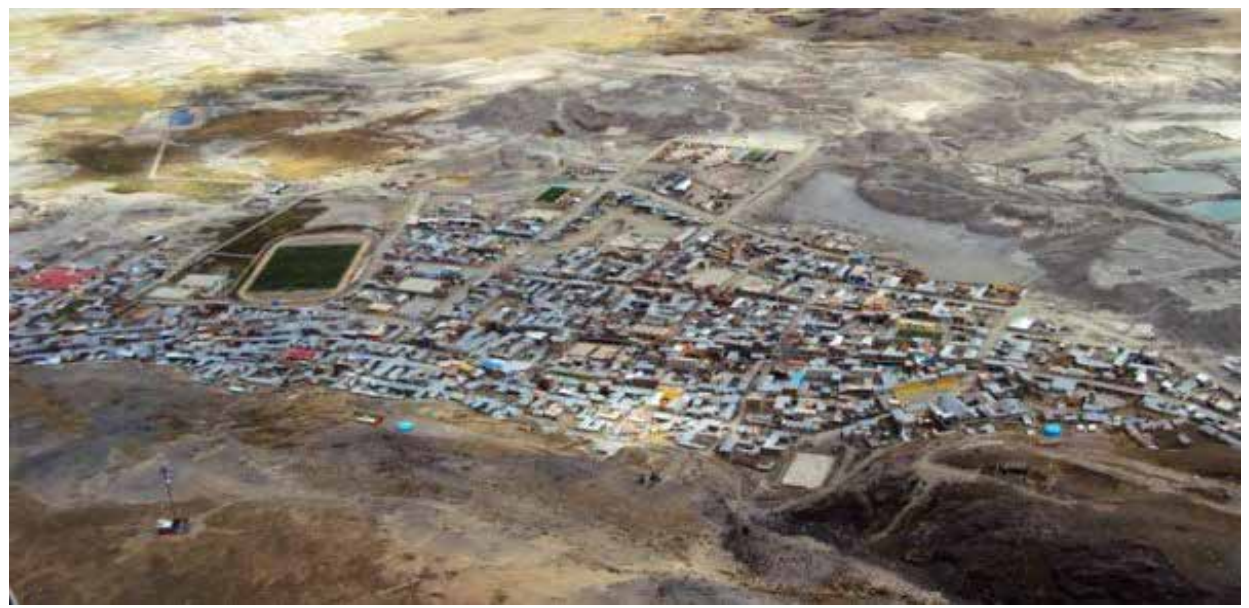

Fuente: http://larepublica.pe/18-11-2013/policia-alista-intervencion-en-otras-tres-minas-ilegales-enregion-puno $(20 / 03 / 2017)$

Figura 6. Imagen Landsat 2014 de la zona minera denominada Ancocala (Resol. 30 m.)

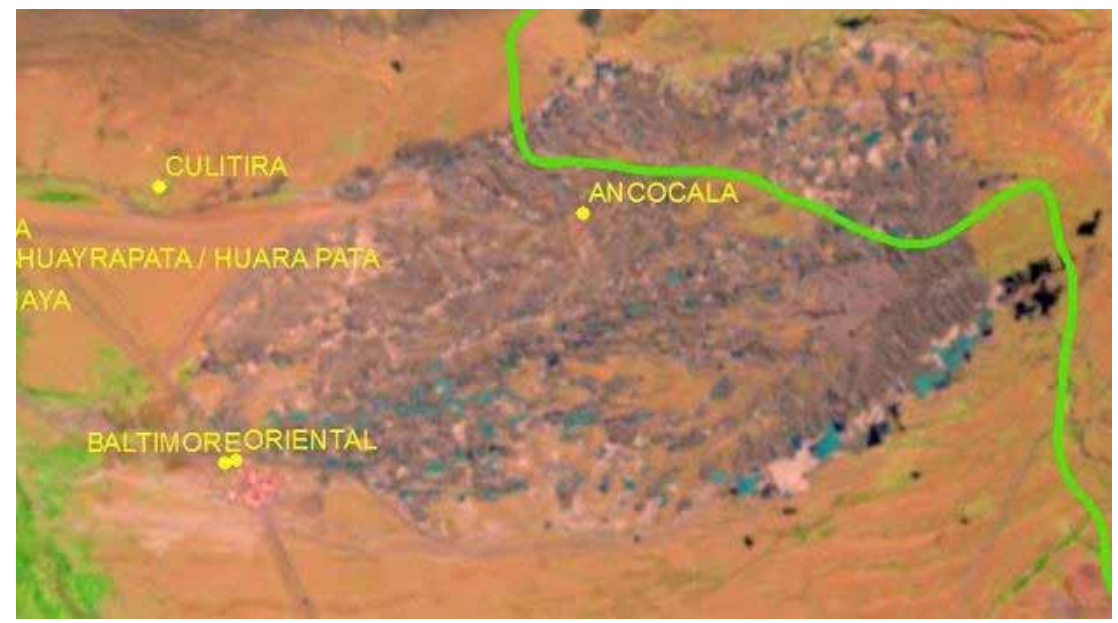

Fuente: Giraldo (2017). 
Figura 7. Imagen Spot 2014 de la zona minera denominada Ancocala (Resol. 1,5 m.)

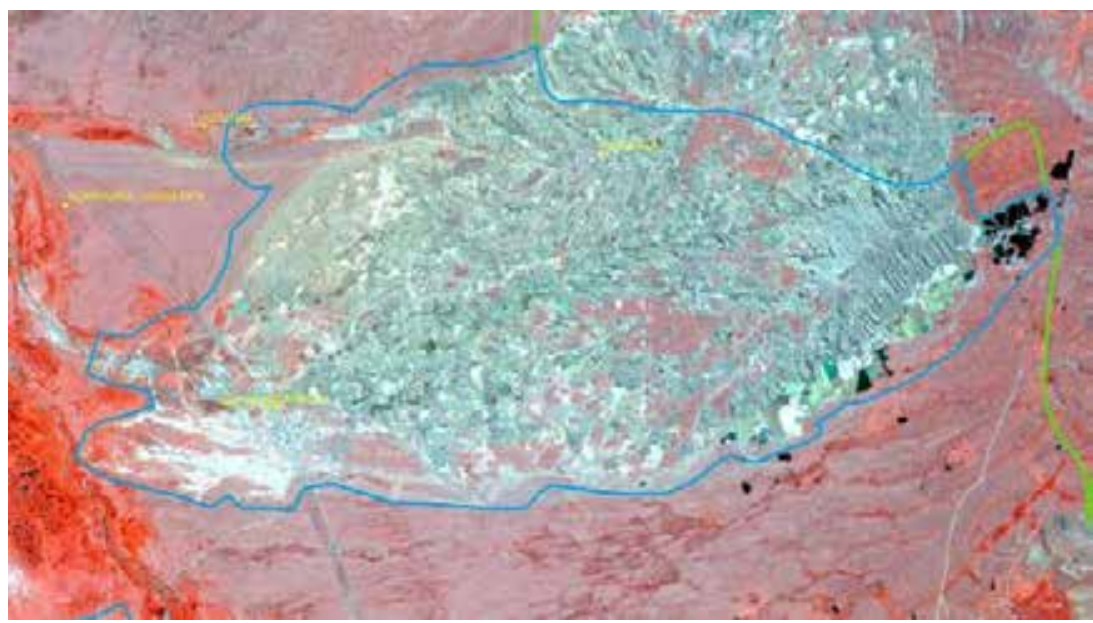

Fuente: Giraldo (2017).

Por las características del ámbito, las actividades económicas que se pueden dar únicamente son la ganadería, la conservación, la urbanización y la minería. Las dos primeras son de poco impacto a este tipo de paisaje. En el caso de la urbanización es de poca extensión y se concentra de modo estricto a los alrededores de los principales centros poblados (Ananea, la Rinconada y Cerro Lunar); por ende, cualquier cambio en el uso del suelo de tamaño considerable (especialmente que presente remoción de la cobertura vegetal) se deberá al desarrollo de actividades mineras.

Precisamente, con el objetivo de conocer la extensión del área afectada que se tenía por minería, se procesó la imagen satelital más reciente que se disponía a la fecha de iniciado el trabajo (2015), y se logró estimar que la minería aurífera habría alterado una extensión aproximada de 5060 hectáreas en total, de las cuales 3167 corresponden al ámbito del Ananea-Chaquiminas-Pampa Blanca, 1825 a Ancocala-Oriental y 68 al sector Huacchani.

Por su fácil identificación a través de imágenes satelitales, la posibilidad de medir su extensión con sistemas de información geográfica, y la libre disponibilidad de galerías web de imágenes, en este estudio se tomó el cambio de uso de suelos (CUS) como indicador para determinar la dinámica temporal de expansión territorial que tuvo la minería aurífera informal en la cuenca alta del río Ramis.

Es importante señalar que el cambio de uso de suelos (CUS) es un proceso que se da en el territorio como consecuencia de la ocurrencia de algún evento socioeconómico en particular, que involucra la intervención del ser humano sobre un determinado terreno para cambiar el tipo de aprovechamiento que se le da en ese momento, cuyo nuevo uso le brindaría mayores beneficios en el futuro (Giraldo Malca, 2017). 
Gracias al desarrollo de tecnologías informáticas y las tendencias de intercambio de información a nivel global, hoy en día se tiene a disposición una serie de plataformas web de libre disponibilidad que publican imágenes capturadas alrededor de todo el mundo. Una de estas plataformas es la denominada GLOVIS (Global Visualization Viewer - http://glovis.usgs.gov/) desarrollada por la United States Geological Survey (USGS) del gobierno de los Estados Unidos que dispone de la mayoría de las imágenes capturadas por los satélites Landsat 5, 7 y 8 desde el inicio de sus operaciones en los años 80 hasta la actualidad. Para nuestro fin, cuenta con imágenes multiespectrales de buena calidad para casi todos los años desde 1984 hasta 2015 (periodo de análisis), con las cuales se puede ver cómo ha ido cambiando la situación ambiental del ámbito (ver Figuras 8 y 9).

Figura 8. Imagen satelital del ámbito de estudio de 1984

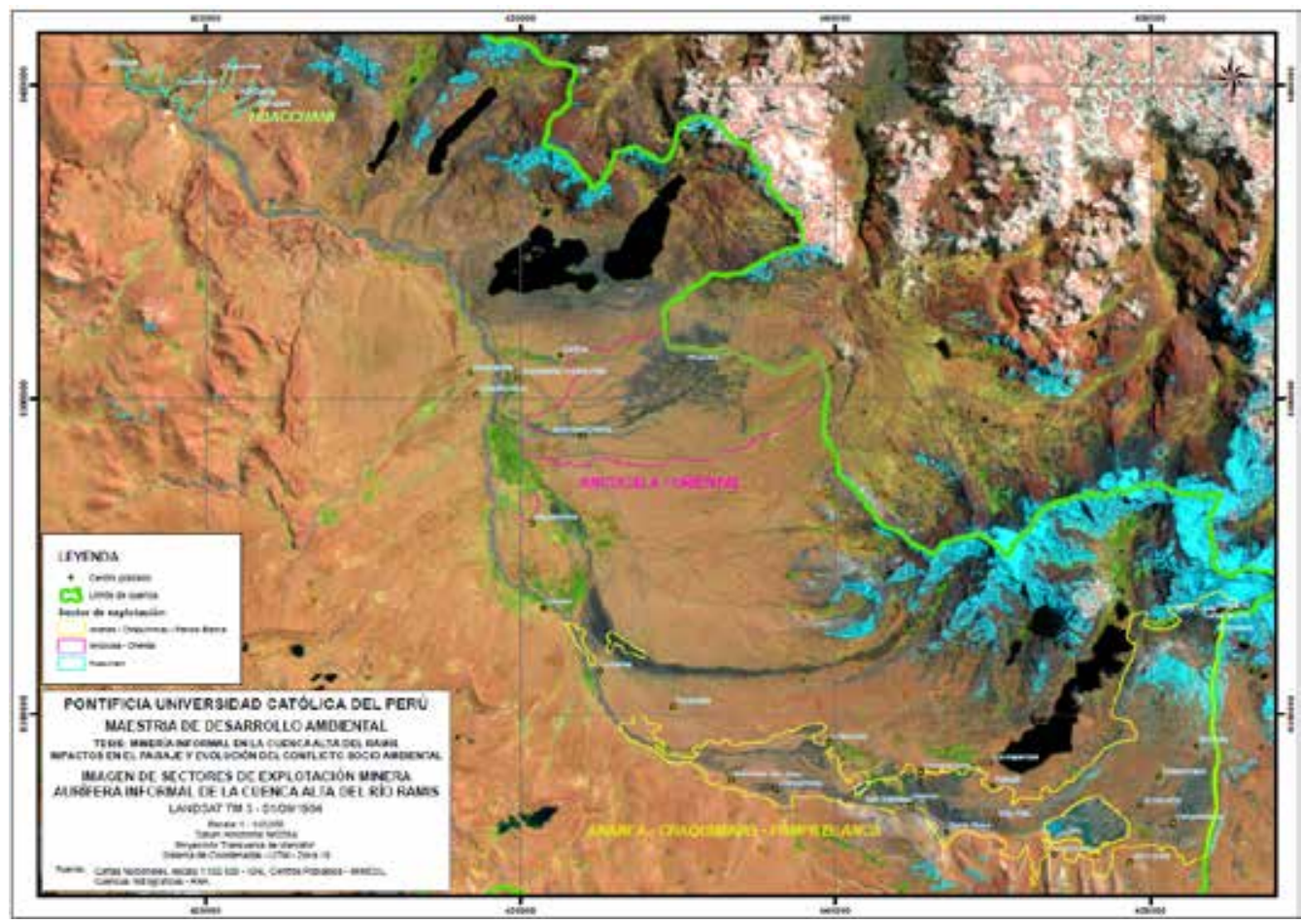

Fuente: Giraldo (2017). 
Figura 9. Imagen satelital del ámbito de estudio de 2015

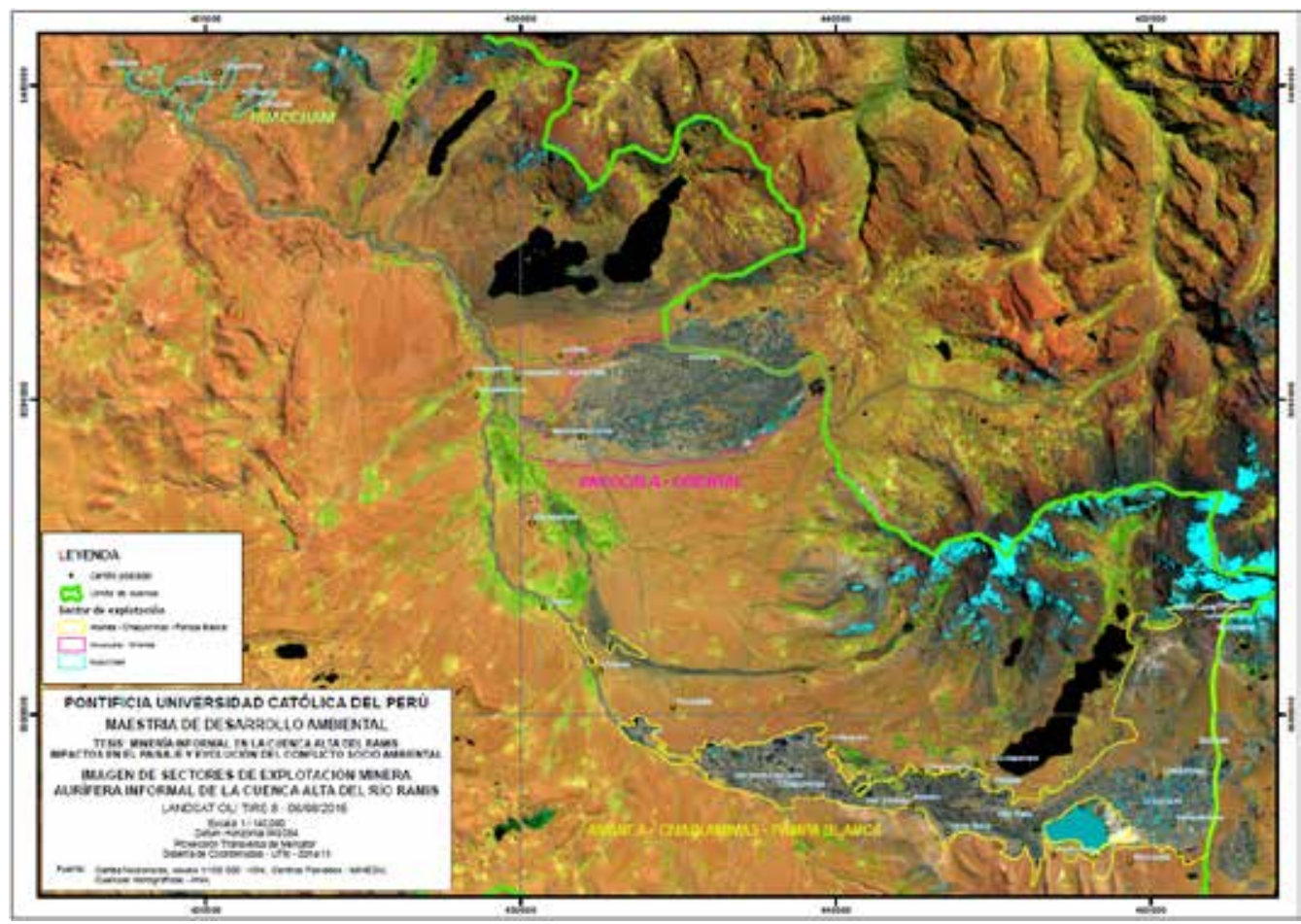

Fuente: Giraldo (2017).

\section{LA TELEDETECCIÓN Y SU APLICACIÓN EN LA IDENTIFICACIÓN DE CAMBios}

La teledetección es la ciencia y arte de obtener información de un objeto analizando los datos adquiridos mediante algún dispositivo (sensor remoto) que no está en contacto físico con él (Martínez Muñoz, 2005), y que es transportado por un satélite o aeronave. En la práctica, es utilizado para describir la recolección y análisis de datos hecha por instrumentos transportados en o sobre la atmósfera (Butler, Mouchot, Barale, \& LeBlanc, 1990). Estos sensores detectan y miden parámetros físicos como la radiación, y los convierte en valores numéricos que permiten su almacenamiento y transmisión, siendo sus principales productos las imágenes satelitales (multiespectrales, estereoscópicas, radar, láser) y fotografías aéreas, que han demostrado sus bondades en el estudio del territorio al proveer datos primarios altamente confiables y de buena precisión.

Precisamente el uso de imágenes multiespectrales de los satélites Landsat es ideal para conocer y evaluar la composición del paisaje de un ámbito tan extenso como la cuenca alta del río Ramis, y saber cómo ha cambiado en el tiempo. Para nuestro estudio se decidió usar estas imágenes por los siguientes motivos: 
a) Cuenta con siete bandas espectrales, que mediante su combinación nos permite tener resultados más precisos para la detección y clasificación de vegetación, con ello generar mapas de cobertura vegetal y de uso del suelo para cada año.

b) Cuenta con el registro histórico de escenas más amplio para nuestra zona de interés.

c) Su disponibilidad a través de internet es gratuita.

Estas imágenes nos muestran la configuración territorial que tenía el ámbito de estudio en un momento determinado, como al inicio del periodo de evaluación en 1984 (línea base), en la cual se pueden identificar y diferenciar con claridad cuerpos de agua (represas, lagunas), nevados, las áreas con cobertura vegetal (bosques, matorrales, pastizales), áreas urbanas y otras zonas sin cobertura vegetal que existían en su momento. Esta identificación puede hacerse tanto mediante interpretación visual como a través de un análisis espectral automatizado, lo cual nos permite obtener mapas confiables de cobertura vegetal y uso del suelo. Si se repite este análisis con imágenes de otras fechas, se podrá hacer la comparación de ambos resultados y determinar los cambios que se hayan podido producir en ese periodo de tiempo. A esto se le denomina «análisis multitemporal».

Las imágenes Landsat permiten hacer un buen análisis de CUS, pero no es posible identificar de modo visual el tipo de actividad que lo haya producido debido a su resolución espacial (30 metros por píxel). Por este motivo, se procuró tener un mecanismo que permita validar los resultados que se obtuvieron del análisis multiespectral con imágenes Landsat, y se optó por utilizar las galerías de imágenes de alta resolución de la aplicación web Google Earth, los servicios disponibles en el software QGIS (Bing Maps, Google Maps), y una imagen de satélite SPOT 6 del año 2014 de alta resolución (1,5 metros por pixel), las cuales si permiten diferenciar de forma clara aquellas zonas que han sido intervenidas por actividades mineras, de aquellas que sufrieron cambios en su cobertura vegetal por otras causas (antrópicas o naturales).

Figura 10. Vista de la ciudad de Ananea desde la galería de imágenes de alta resolución de Bing Maps

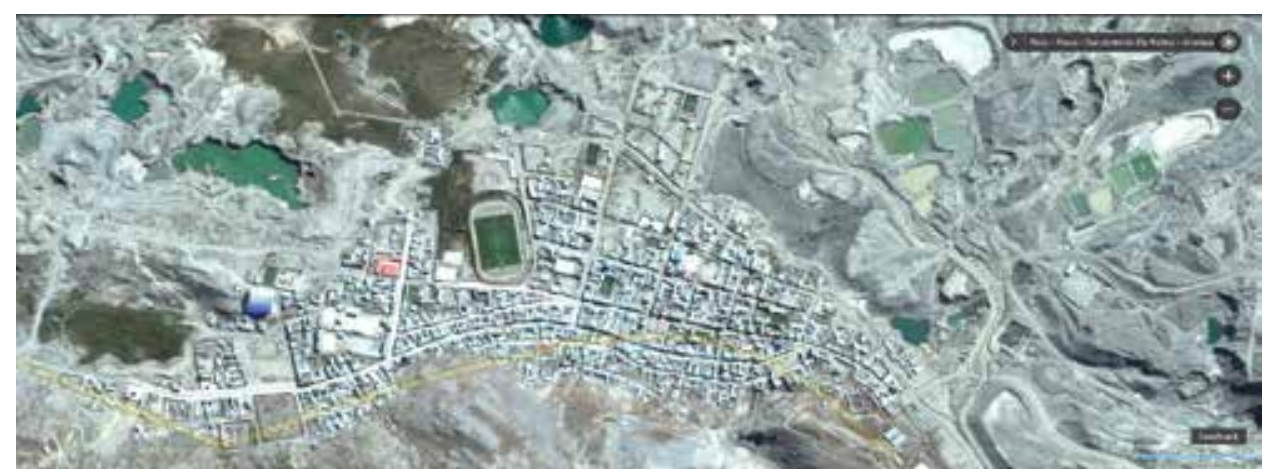

Fuente: https://www.bing.com/maps (recuperado 01/12/2016). 


\section{ANÁlisis de CAMbios EN LA CUENCA ALTA}

Las imágenes satelitales de catálogo son un registro histórico de fotografías que permite ver cómo era un determinado lugar años atrás. Esta construye una buena fuente de información que mostrará la composición del paisaje en un determinado momento y en la cual, al comparar con escenas de distinta fecha, se puede identificar cambios que se hayan producido en el territorio en el periodo de tiempo que separa las fechas de toma de cada una de las imágenes.

Las imágenes Landsat fueron el insumo principal para esta evaluación. La imagen multiespectral más antigua disponible de la zona fue tomada el primero de septiembre de 1984, y la más reciente del seis de agosto de 2015 (la última escena de buena calidad disponible al mes de abril de 2016 cuando se desarrolló el presente análisis), todas obtenidas de la plataforma web GLOVIS, de la cual se descargaron las siguientes escenas:

Tabla 2. Escenas de imágenes de satélite Landsat utilizadas en el presente estudio (1984-2015)

\begin{tabular}{ccccl}
\hline Imagen & Path & Row & Fecha de toma & \multicolumn{1}{c}{ Satélite - Sensor } \\
\hline LT50020701984245CUB00 & 002 & 070 & $01 / 09 / 1984$ & Landsat 5 - TM \\
LT50020701986138CUB00 & 002 & 070 & $18 / 05 / 1986$ & Landsat 5 - TM \\
LT50020701988160CUB00 & 002 & 070 & $08 / 06 / 1988$ & Landsat 5 - TM \\
LT50020701990197CUB00 & 002 & 070 & $16 / 07 / 1990$ & Landsat 5 - TM \\
LT50020701992139CUB00 & 002 & 070 & $18 / 05 / 1992$ & Landsat 5 - TM \\
LT50020701994144CUB00 & 002 & 070 & $24 / 05 / 1994$ & Landsat 5 - TM \\
LT50020701996182CUB02 & 002 & 070 & $30 / 06 / 1996$ & Landsat 5 - TM \\
LT50020701998155COA02 & 002 & 070 & $04 / 06 / 1998$ & Landsat 5 - TM \\
LT50020702000177XXX02 & 002 & 070 & $25 / 06 / 2000$ & Landsat 5 - TM \\
LT50020702001147CUB01 & 002 & 070 & $27 / 05 / 2001$ & Landsat 5 - TM \\
LE70020702002206EDC00 & 002 & 070 & $25 / 07 / 2002$ & Landsat 7 - ETM+ \\
LT50020702003185CUB00 & 002 & 070 & $04 / 07 / 2003$ & Landsat 5 - TM \\
LT50020702004156CUB03 & 002 & 070 & $04 / 06 / 2004$ & Landsat 5 - TM \\
LT50020702005190COA01 & 002 & 070 & $09 / 07 / 2005$ & Landsat 5 - TM \\
LT50020702006145CUB00 & 002 & 070 & $25 / 05 / 2006$ & Landsat 5 - TM \\
LT50020702007164CUB00 & 002 & 070 & $13 / 06 / 2007$ & Landsat 5 - TM \\
LT50020702008199CUB00 & 002 & 070 & $17 / 07 / 2008$ & Landsat5 - TM \\
LT50020702009169CUB00 & 002 & 070 & $18 / 06 / 2009$ & Landsat 5 - TM \\
LT50020702010204CUB00 & 002 & 070 & $23 / 07 / 2010$ & Landsat 5 - TM \\
LT50020702011191CUB00 & 002 & 070 & $10 / 07 / 2011$ & Landsat 5 - TM \\
LE70020702012202CUB03 & 002 & 070 & $20 / 07 / 2012$ & Landsat 7 - ETM+ \\
LC80020702013180LGN00 & 002 & 070 & $29 / 06 / 2013$ & Landsat 8 - OLI_TIRS \\
LC80020702014167LGN00 & 002 & 070 & $16 / 06 / 2014$ & Landsat 8 - OLI_TIRS \\
LC80020702015218LGN00 & 002 & 070 & $06 / 08 / 2015$ & Landsat 8 - OLI_TIRS \\
\hline
\end{tabular}

Fuente: Giraldo (2017). 
El periodo de análisis suma un total de treinta y un años, dividiendo este periodo en dos partes: el primero de 1984 a 2000 donde se hizo la comparación de imágenes cada dos ańos, y el segundo de 2001 a 2015 realizado de forma anual. La diferenciación en el detalle del análisis se sustenta en que para el segundo periodo se manifestaron los eventos que habrían tenido una mayor influencia en la expansión o contracción de la actividad minera aurífera informal, por ejemplo el récord histórico del precio internacional del oro al alcanzar los 1923,20 dólares estadounidenses por onza $(06 / 09 / 2011)$, las principales manifestaciones del conflicto socioambiental en la cuenca (2004, 2007 y 2009, las cuales se detallaran más adelante), y el inicio de las acciones de interdicción contra la minería ilegal (2012).

Para el análisis fue necesario normalizar las condiciones de reflectancia a todas las escenas (Corrección Radiométrica), esto debido a que cada imagen fue capturada desde una ubicación del satélite diferente, en condiciones atmosféricas y de iluminación distintas (altura del sol, inclinación y dirección de los rayos solares), las cuales en este tipo de procesos son altamente relevantes porque pueden distorsionar los resultados finales. Para ello se utilizó la herramienta «IAR Reflectance Correction» del software ENVI 5.3.1 que permite normalizar las características de todas las escenas trabajadas a una condición hipotéticamente estándar a lo que, en términos técnicos, se denomina determinación de valores de reflectancia.

Tras realizar la corrección radiométrica de las veinticuatro escenas a procesar, se llevó a cabo el cálculo del Índice de Vegetación de Diferencia Normalizada (NDVI) ${ }^{4}$ en cada una de ellas, con el que se obtiene datos de presencia, vigorosidad y distribución de vegetación en el ámbito de estudio. Al comparar las «bandas roja e infrarroja cercana" ${ }^{5}$ se le aplica un algoritmo matemático que resalta todos los píxeles en los que haya presencia de clorofila, por ende, que presentan algún tipo de vegetación.

En ese sentido, se aprovecharon las imágenes NDVI para encontrar los lugares donde hubo cambios en la cobertura vegetal para hacer una comparación digital de dos escenas, en las cuales el software aplicó una resta entre el valor de cada píxel de la imagen «A» con el pixel que tiene su misma ubicación en la imagen «B». Como resultado, se obtuvo una nueva imagen en la que cada píxel tenía como valor la diferencia resultante de la operación anterior. Finalmente, se clasificó esta nueva imagen, y se agruparon aquellos píxeles con valores próximos a cero que representan los lugares donde no hubo modificaciones en la cobertura vegetal, y aquellos que presenten valores más

\footnotetext{
4 NDVI: (Normalized Difference Vegetation Index) es el índice de vegetación más utilizado, se utiliza para estimar la cantidad, calidad y desarrollo de la vegetación con base a la medición de la intensidad de la radiación de ciertas bandas del espectro electromagnético que la vegetación emite o refleja. http:// mappinggis.com/2015/06/ndvi-que-es-y-como-calcularlo-con-saga-desde-qgis/

5 Bandas espectrales en las que la clorofila tiene sus niveles de menor y mayor reflectividad respectivamente en el espectro electromagnético.
} 
altos que correspondían a lugares donde efectivamente hubo un cambio importante en la cobertura vegetal como el producido por procesos de reforestación o deforestación.

Este principio permite diseñar la metodología a utilizar en este análisis bajo la siguiente hipótesis: al comparar por diferencia dos escenas de NDVI correspondientes a dos fechas distintas, se logra identificar cambios importantes en la cobertura vegetal, como las generadas por la remoción de suelos que se da en la explotación minera aurífera informal.

De acuerdo a la bibliografía revisada, todos aquellos píxeles cuyo valor NDVI es menor a cero "corresponden a cubiertas artificiales, zonas de agua, nubes, rocas", las que se encuentran entre 0 y 0,1 son aquellos suelos sin cobertura vegetal, observándose recién presencia de vegetación fotosintética a partir de valores superiores a 0,15 de NDVI (Cartaya, Zurita, Rodríguez y Montalvo, 2015). Sin embargo, en el ámbito de interés se pudo observar que praderas cubiertas de ichu (Stipa ichu) presentan valores entre 0 y - 0,1 , probablemente debido a que el ichu en época de secano (mayo a noviembre) presentan un estado fenológico de senescencia caracterizada por su marchitez (bajo contenido de agua y clorofila) que sumado a la baja concentración de matas por metro cuadrado que caracteriza a los ecosistemas de páramo altoandino, generan un bajo nivel de NDVI en la imagen procesada.

Acto seguido, se comparó los resultados NDVI de los diferentes años de forma correlativa utilizando la herramienta Image Change Workflow, que detecta los cambios entre los píxeles de ambas imágenes, siguiendo todos los pasos recomendados por el software ENVI 5.3 y que se enumeran a continuación:

1. Selección de las dos imágenes a procesar (inicio y fin del periodo).

1. Generación de la imagen de registro (Skip Image Registration).

3. Selección del método de cambio para la detección de diferencias (Image Difference)

4. Generación de la imagen de diferencias.

5. Aplicación del Thersholding (Apply Thersholding)

6. Selección del Thersholding de cambios (Increase and Decrease - Otsu's)

7. Reajuste del valor de detección de cambios en el Thersholding de decrecimiento a 0,20 (tras un primer ejercicio se descartó homogeneizar el valor a todas las escenas)

8. Aplicar un filtro de smoothing kernel size 3 (tras un primer ejercicio se descartó este paso)

Tras obtener un primer resultado con la aplicación de esta metodología, se pudo observar que las detecciones encontradas corresponden a zonas donde, efectivamente, se produjo la remoción de la cobertura vegetal, pero también hubo otras causas que obedecen a cambios en la vigorosidad de la vegetación (que no implican la remoción de la misma). Esto se debe a que el algoritmo utilizado sirve para identificar cambios 
en los valores del NDVI en un rango determinado, no interesando si este se produce por el cambio de una vegetación gramínea (bajo NDVI) a suelo sin cobertura (NDVI con valor negativo) producto de un CUS, o de un bofedal húmedo (NDVI alto) a un bofedal seco (NDVI bajo) generado por la ocurrencia de una sequía.

Esta observación dejó en evidencia que no se podía aplicar un único valor de ajuste Thersholding de decrecimiento a todos los periodos analizados (paso número 7), ya que las diferencias que se presentan en zonas detectadas eran más evidentes en años húmedos (con mayor precipitación) cuando la vegetación tiene una mayor vigorosidad, que en años más secos donde la vegetación tiene una reflectancia menor y que genera diferencias de NDVI más reducidas.

Figura 11. Imagen de alta resolución del sector Chaquiminas - Ananea, se aprecia con claridad que la zona es explotada por actividades mineras

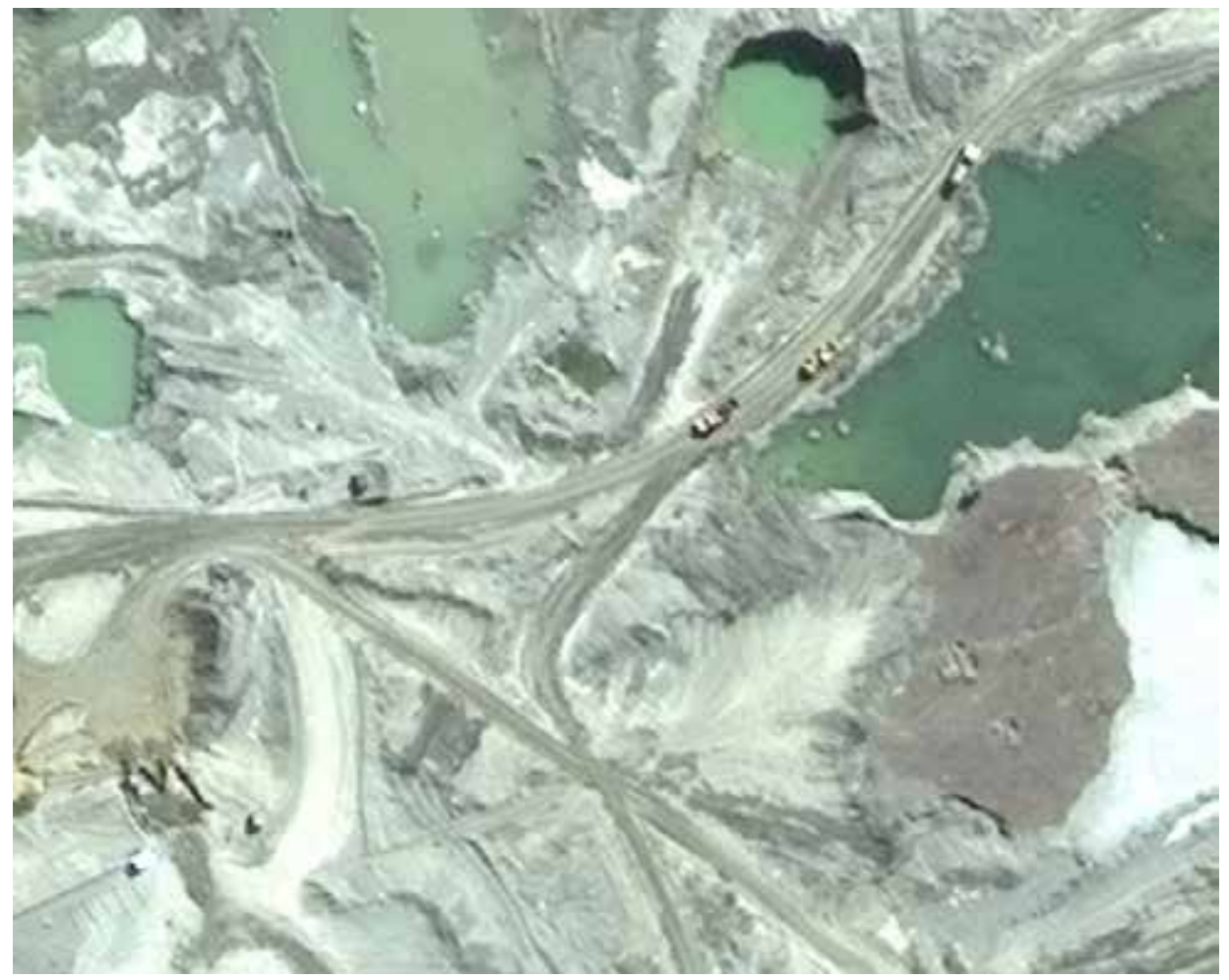

Fuente: Plataforma Web Bing Maps. Imagen DigitalGlobe - 0,5 metros (recuperado 01/12/2016)

Otra observación que se encontró en los mapas resultantes fue que no reconocía como «área afectada» la totalidad de sitios donde se produjo la remoción de la cobertura vegetal entre 1984 y 2015, los mismos que se podían apreciar en una interpretación visual de las dos imágenes multiespectrales. Esto se debe a que dentro de las técnicas de 
procesamiento de imágenes se utiliza con frecuencia herramientas denominadas «filtros» cuyo objetivo es suavizar la imagen resultante, habiendo antes descartado unidades pequeñas (conformadas por pocos píxeles), que rompan la homogeneidad de la unidad predominante. En ese sentido, los sitios afectados en cada periodo analizado (de uno o dos años), en realidad, corresponden a pequeñas operaciones mineras desperdigadas en los alrededores de la zona de explotación antigua, que en muchos casos no superan los $8100 \mathrm{~m}^{2}$ (9 píxeles o 90x90 metros) valor mínimo que reconoce al filtro 3×3 aplicado en el procesamiento antes descrito (paso número 8), y estas pequeñas áreas afectadas eran descartadas por el software. Por esta razón, se decidió eliminar este paso en el procesamiento de las imágenes.

Asimismo, se tuvo problemas con el procesamiento de la escena LE70020702012202CUB03. Esto afectó los resultados de dos periodos de análisis (20112012 y 2012-2013), al presentar defectos por fallas en el mismo sensor $L 7 E T M+$, el cual genera un bandeo en las imágenes capturadas, por lo que se decidió excluirlo del análisis.

Por lo antes expuesto, se volvió a realizar el proceso de análisis digital de todas las escenas, considerando los ajustes a la metodología que fueron mencionados con anterioridad, y se aplicó una técnica para restringir el análisis estrictamente al ámbito afectado por la minería informal, la cual consistió en delimitar el área real de uso minero utilizando la imagen satelital SPOT de alta resolución — 1,5 m de píxel— del ańo 2014 y las disponibles en las plataformas web del Google Earth y del Bing Maps. De esta manera, se descartaron todas las detecciones encontradas en zonas cercanas que se hayan producido por otros fenómenos ajenos a la actividad minera.

Figura 12. Imagen de alta resolución del sector Ancocala - Cuyocuyo, permite apreciar claramente que la zona es explotada por actividades mineras

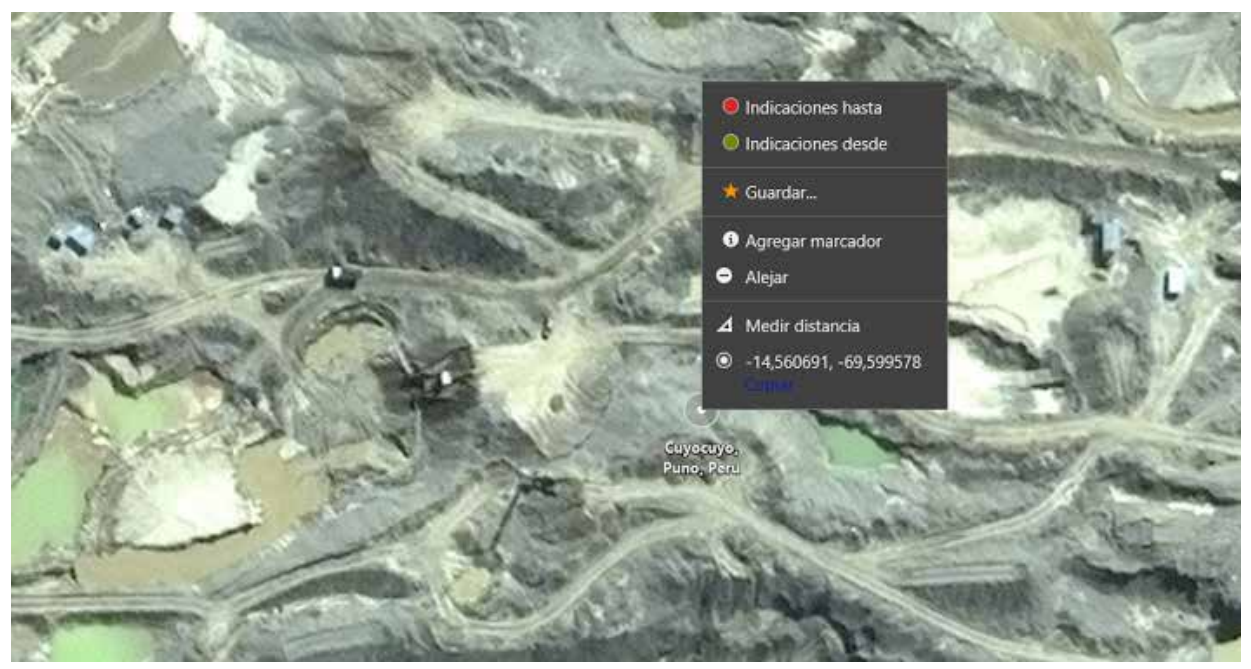

Fuente: Plataforma Web Bing Maps. Imagen DigitalGlobe - 0,5 metros (recuperado 01/12/2016) 


\section{RESULTADOS Y ANÁLISIS}

La primera imagen de satélite procesada muestra que a la fecha de su captura (01/09/1984) ya existía un total de 2769 hectáreas utilizadas para la explotación minera de oro, y los resultados que se obtuvieron permitieron identificar, ubicar y cuantificar la superficie total en la que se produjo la eliminación de la cobertura vegetal (cambio de uso de suelos) por efecto de la minería en cada uno de los periodos. Asimismo, con la ayuda de los sistemas de información geográfica el análisis se aplicó de forma individualizada para cada uno de los tres sectores en los que se dividió el ámbito de estudio -1. Ananea-Chaquiminas- Pampa Blanca; 2. Ancocala - Oriental; 3. Huacchani-, cuyos resultados (ver Tabla 3 y Figura 8) nos permiten apreciar patrones de evolución diferentes para cada uno de ellos, que serán descritos a continuación.

Tabla 3. Resultado del análisis de cambio de uso de suelos por sectores y periodos de evaluación

\begin{tabular}{ccrrr}
\hline $\begin{array}{c}\text { Período de } \\
\text { análisis }\end{array}$ & $\begin{array}{c}\text { Ananea - Chaquiminas - } \\
\text { Pampa Blanca }\end{array}$ & Ancocala & Huacchani & $\begin{array}{c}\text { Total general } \\
\text { (ha) }\end{array}$ \\
\hline $1984-1986$ & 96,41 & 18,47 & 2,84 & 117,72 \\
$1986-1988$ & 10,41 & 22,15 & 16,02 & 48,58 \\
$1988-1990$ & 1,26 & 5,06 & 1,08 & 7,40 \\
$1990-1992$ & 6,65 & 3,24 & 0,18 & 10,07 \\
$1992-1994$ & 1,00 & 1,98 & & 2,98 \\
$1994-1996$ & 5,40 & 13,16 & 2,79 & 21,35 \\
$1996-1998$ & 2,99 & 0,81 & & 3,80 \\
$1998-2000$ & 2,49 & 4,50 & 0,27 & 7,26 \\
$2000-2001$ & 7,22 & 1,98 & 0,27 & 9,47 \\
$2001-2002$ & 7,37 & 2,93 & & 10,30 \\
$2002-2003$ & 16,86 & 4,05 & & 20,91 \\
$2003-2004$ & 56,03 & 4,86 & 1,20 & 62,09 \\
$2004-2005$ & 7,30 & 11,71 & 0,36 & 19,38 \\
$2005-2006$ & 134,01 & 2,88 & 0,63 & 137,52 \\
$2006-2007$ & 32,98 & 0,45 & 0,45 & 33,88 \\
$2007-2008$ & 8,97 & 0,27 & 0,09 & 9,33 \\
$2008-2009$ & 69,26 & 74,76 & 0,27 & 144,29 \\
$2009-2010$ & 184,75 & 265,27 & 3,29 & 453,31 \\
$2010-2011$ & 185,77 & 244,53 & 23,88 & 454,18 \\
$2011-2013$ & 148,03 & 198,46 & 1,85 & 348,33 \\
$2013-2014$ & 142,27 & 52,66 & 2,69 & 197,63 \\
$2014-2015$ & 97,10 & 73,30 & 0,53 & 170,94 \\
\hline Total general (ha) & 1224,53 & 1007,47 & 58,69 & 2290,70 \\
\hline
\end{tabular}

Fuente: Giraldo (2017). 
Figura 13. Resultados del análisis de cambio de usos de suelos generado por minería informal en la cuenca alta del río Ramis

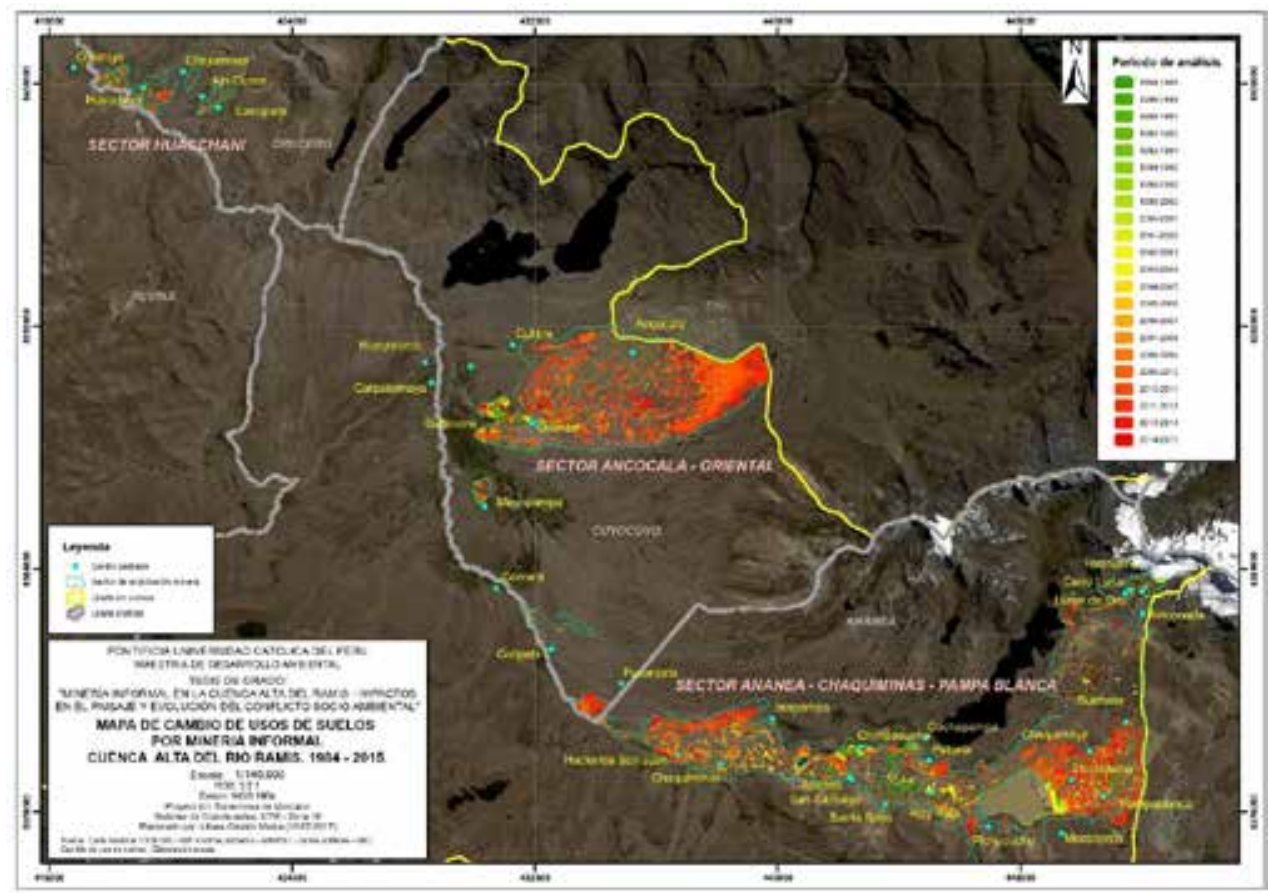

Fuente: Giraldo (2017).

Los resultados del análisis de CUS nos muestran que la mayor expansión territorial del ámbito explotado por la minería informal en la cuenca alta del río Ramis se da entre los años 2009 y 2011 — 907,49 ha- que constituye alrededor del 39,6\% de la superficie alterada por minería en todo el periodo de evaluación —1984-2015_, que presenta registros con valores anuales superiores a las 450 hectáreas. Sin embargo se tiene otros periodos con registros considerablemente altos como fueron 1984-1986 2005-2006, 2008-2009, 2011-2013, 2013-2014 y 2014-2015, cuya superficie alterada superaron las cien hectáreas.

6 Tener en cuenta que este período está constituido por dos ańos, por lo que en promedio anual estaría cerca de las 56 ha. 
Figura 14. Resultado del análisis de cambio de uso de suelos total en el ámbito de interés por periodo de evaluación

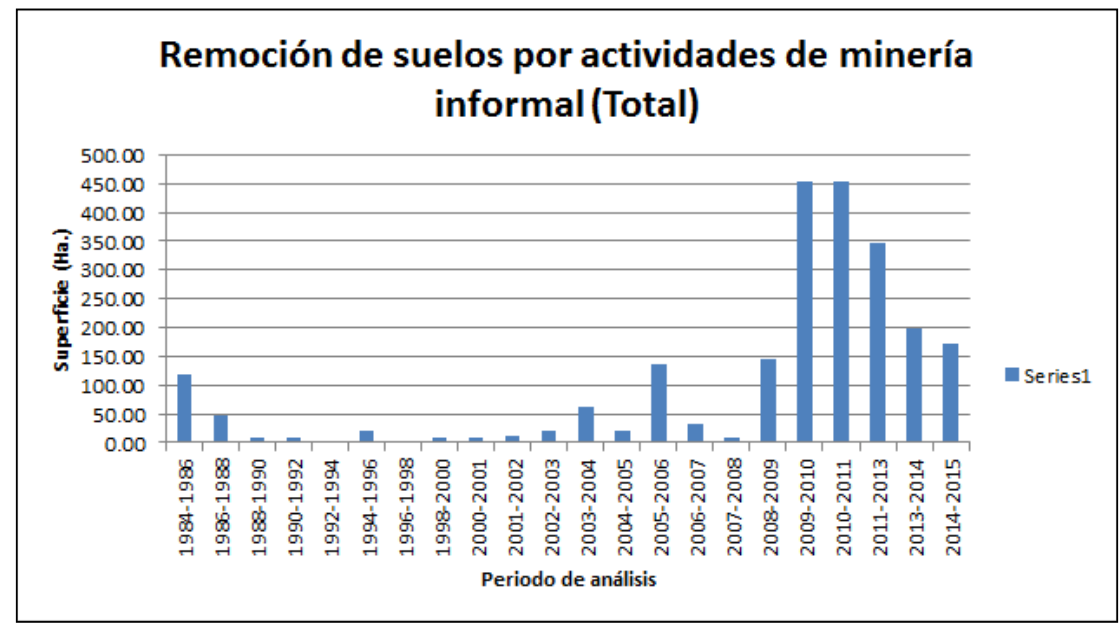

Fuente: Giraldo (2017).

De acuerdo a este indicador, es evidente que el mayor auge de la minería aurífera en nuestro ámbito se da entre los años 2008 y 2015, registrando los valores más altos y contabilizando un total de 1768,68 hectáreas (77\% de la expansión total). Sin embargo, se aprecian otros dos valores relativamente altos en los periodos 1984-1986 y 2005-2006 los cuales llegan a superar cada uno las cien hectáreas. Estos dos casos debieron tener eventos particulares que hayan impulsado su respectiva expansión, que hipotéticamente serían distintos al que motivó el momento de expansión principal (2008-2015).

En el sector Ananea-Chaquiminas-Pampa Blanca, se puede apreciar que, a diferencia de los otros dos sectores, presenta hasta cuatro momentos diferentes en los que tuvo una expansión superior al promedio, correspondiente a los períodos 1984-1986, 2003-2004, 2005-2006 y 2008-2015. Precisamente, es el último periodo el único en el que coincide con los otros dos sectores. En el caso de los tres periodos anteriores, solo este sector muestra un crecimiento alto del área con explotación minero. De ese modo, entre 1984 y 1986 se presentó un valor extrańamente alto en el CUS (118 ha) considerando que se encuentra en un momento alejado al boom de los metales - gran incremento del precio internacional-, pero al contrastarlo con la cronología de hechos históricos del conflicto, observamos que coincide con las fechas en que Minero Perú explotó el yacimiento denominado San Antonio de Poto (Proyecto GAMA, 2004) del sector Pampa Blanca, donde se concentró el mayor porcentaje de alteración del suelo para este periodo sumando más de 96 ha $-82 \%$ del valor de CUS registrado para el periodo 1984-1986-. 
Figura 14. Resultado del análisis de cambio de uso de suelos por sectores y periodos de evaluación

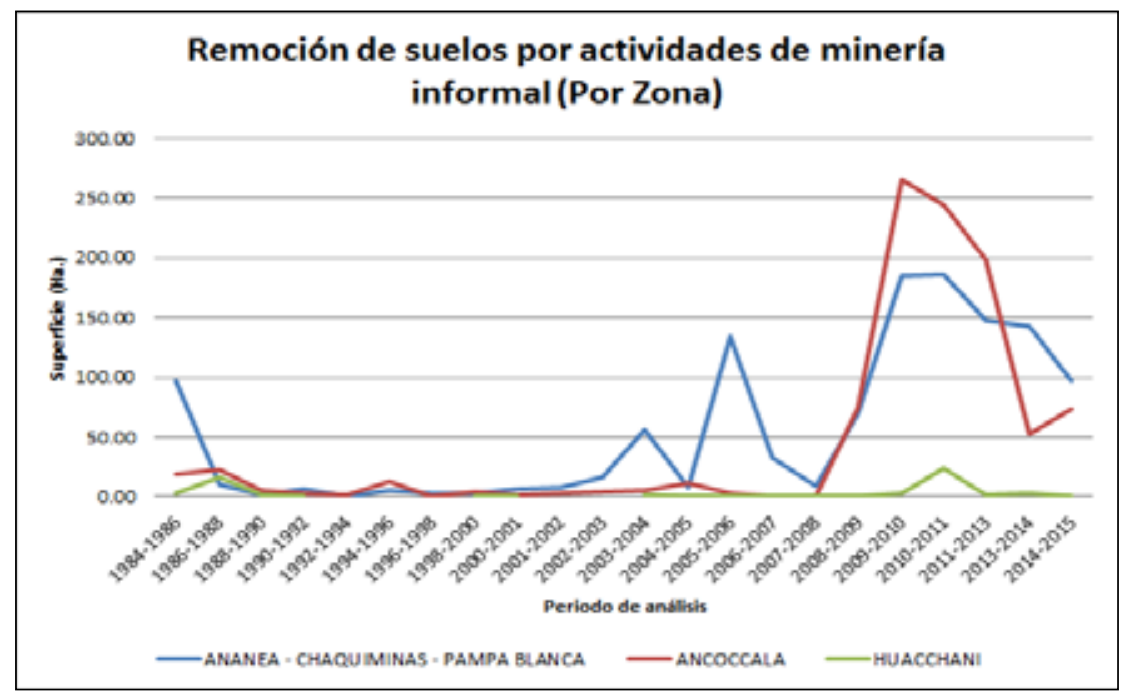

Fuente: Giraldo (2017).

El segundo incremento llamativo del CUS se da entre los años 2003 y 2004, precisamente en el sector Ananea-Chaquiminas-Pampa Blanca, que, tras un largo periodo de registros bajos (inferior a las 17 ha por ańo), este se incrementa presentando un área alterada de 54 hectáreas, la cual temporalmente coincide con la primera invasión de mineros informales a las concesiones de CENTROMIN y el inicio de sus operaciones en la zona de Chaquiminas, asunto que fue abordado en las reuniones que sostuvieron representantes de la empresa y dirigentes mineros comunales en agosto y septiembre de 2004 (DREM PUNO, 2005).

El tercer pico que alcanza el crecimiento del área afectada por la minería informal se presenta entre 2005 y 2006 llegando a la 137,52 hectáreas, el cual coincide temporalmente con la renuncia de Centromin Perú a las concesiones del proyecto minero San Antonio de Poto en agosto de 2005 (Chaquiminas y Pampa Blanca) y su transferencia a Cecomsap y otras cooperativas mineras que trabajaban en la zona (Diario El Peruano, 2005).

La coincidencia más evidente entre las líneas que muestran la evolución de la cotización del oro y el área de expansión minera aurífera (CUS), se da a partir de 2009 y se extiende hasta 2013. Este periodo presenta sus máximos valores registrados en todos los sectores lo cual confirma la hipótesis inicial, que indica que el principal factor que influye en la expansión o contracción de la explotación de oro informal es precisamente la variación del precio internacional del oro. 
A partir del año 2013 hay una ligera caída del precio internacional del oro, y se repliega su valor promedio a 1410,96 dólares estadounidenses la onza Esto coincide con una reducción importante de los niveles de expansión del área explotada. Sin embargo, también coincide cronológicamente con el inicio de las acciones de interdicción contra la minería ilegal en las localidades de Ananea (noviembre de 2013) y Ancocala (febrero de 2014), lo que podría suponer que esta fue la causante de este fenómeno, pero a pesar de la reducción en los niveles de expansión de la minería aurífera, sus registros en los años siguientes siguen siendo bastante elevados (en relación al promedio de todo el periodo de análisis) y nos hace deducir que salvo una ligera influencia, la ejecución de acciones de interdicción no habrían tenido mayor impacto en la dinámica de explotación aurífera en la zona.

En el caso del sector Ancocala-Oriental, se puede apreciar que desde 1984 hasta 2008 no se tiene cambios significativos en la superficie destinada a la explotación minera, lo que implicaría que en el sector no ocurrieron eventos que incrementaran la dinámica de la actividad y mostraran un crecimiento anual bastante discreto. Esta situación cambia a partir del año 2009, cuando presenta un incremento superlativo del área explotada, llegando a tener los tres registros más altos que se encontraron en nuestra evaluación (265, 245 y 198 hectáreas) de forma consecutiva entre 2009 y 2013, los cuales superan incluso al valor más alto que haya podido registrar del sector Ananea-Chaquiminas-Pampa Blanca — periodo 2010-2011: 185,77 hectáreas-.

En el caso del sector Huacchani, por tener un área mucho menor que los otros dos sectores, no se ve mayor cambio en el patrón de expansión minera, que presenta valores marginales mucho más expuestos al error estadístico. Sin embargo, el periodo que muestra la mayor expansión minera es de 2010 a 2011, lo cual coincide con los otros sectores.

Se puede, además, deducir, al ver los resultados obtenidos, que la ejecución de acciones de interdicción realizadas por el Estado a partir del año 2012 (El Peruano, 2012) no fueron eficaces, al no haber reducido la capacidad operativa de los mineros informales en los ańos siguientes, pero manteniendo registros altos del CUS en la zona en el periodo 2013-2015.

Las tres principales manifestaciones del conflicto socioambiental en la cuenca, que tuvieron como protagonistas a las poblaciones afectadas, se produjeron en los años 1998, 2007 (Asociación SER, 2007) y 2011 (La República, 2011), pudiéndose apreciar que en los ańos siguientes a la ocurrencia de estos eventos se produjeron caídas importantes en los valores del CUS, llegando incluso a presentar un estancamiento de su avance (1998-2000-2001-2002, 2007-2008, 2013-2014). Esta observación nos permitiría argumentar que, en efecto, las manifestaciones de rechazo a la minería por parte de la población de la cuenca media y baja (afectados) tuvo un importante impacto en las operaciones mineras, que no necesariamente haya sido el factor principal, pero sí tuvo una influencia considerable. Esto puede deberse a que las mencionadas protestas 
tuvieron cobertura por parte de la prensa nacional, en las cuales se demandaba la intervención de las autoridades, lo que conllevó a recibir la atención por parte de las entidades gubernamentales competentes, la instalación de mesas de diálogo, la intervención de organismos evaluadores y reguladores, entre otros. Con ello se tuvo una mayor presencia del Estado en la zona los siguientes meses, lo que habría impedido a los mineros informales extender sus operaciones, priorizando la conservación del área que ya venían explotando.

La emisión de nueva normativa por parte del gobierno central para fomentar la formalización de la actividad minera $(2002,2004)$, el establecimiento de nuevas medidas de control y sanción hacia las operaciones ilegales (2011, 2013, 2014), no tuvieron mayor impacto en el CUS, ya que en todos los casos en los años siguientes se registraron niveles de expansión iguales o superiores a los años en los que no se contaba con dichas normas.

\section{Conclusiones}

Los resultados obtenidos nos permiten argumentar que el uso de imágenes satelitales y la metodología propuesta para su procesamiento digital e interpretación, constituyen una herramienta perfectamente aplicable para realizar el monitoreo y evaluación multitemporal de actividades que implican algún tipo de modificación en el paisaje como el CUS. Esto se debe a que al trabajar con escenas de fechas pasadas nos da una perspectiva de cómo era el paisaje de un lugar en un momento determinado. Si este es comparado con una o varias imágenes de fecha posterior, nos permite saber cómo el paisaje ha cambiado en el tiempo dándonos la posibilidad de medir con una alta precisión el alcance de dichas modificaciones para cada periodo de tiempo evaluado. En ese sentido, podemos concluir que en este punto se confirma la hipótesis planteada: «Las actividades de minería informal o ilegal que se desarrollan en la cuenca alta del río Ramis, $[\ldots]$ tienen un aprovechamiento extensivo del territorio [...] cuyo crecimiento en el tiempo puede estimarse con el uso de herramientas de percepción remota como las imágenes de satélite».

Existe una relación de dependencia entre la variación del precio internacional del oro y el proceso de CUS en la cuenca alta del río Ramis, en especial cuando se tiene un precio en ascenso, siendo el mayor incentivo para la inversión de capitales, incluso en este tipo de actividades informales. Asimismo, cuando el precio del oro cae, la expansión de las operaciones mineras se reduce. Todo ello nos permite concluir que la dinámica de la minería informal: [...] se acelera con la ocurrencia de eventos como el incremento del precio internacional del oro, y se frena con la caída de su cotización.

Asimismo, la ocurrencia de eventos que manifiestan el conflicto socioambiental entre mineros informales y afectados tiene un importante impacto en el CUS, reduciendo sus niveles de crecimiento en el periodo siguiente a la ocurrencia del evento. Esto se 
debe a la intervención de los organismos competentes que en cumplimiento de sus funciones tienen que atender estos eventos para lograr el levantamiento de huelgas y el restablecimiento del orden interno, lo cual conlleva, de forma implícita, a tener una mayor presencia del Estado en la zona para participar en espacios de diálogo, evaluaciones de campo, y demás compromisos que asuman.

Finalmente, las acciones de intervención del gobierno para el control de la minería informal en la cuenca alta del río Ramis a través de la disposición de normas para su formalización, control de insumos, restricción de comercialización del oro, realización de acciones de interdicción, entre otras, no han tenido el efecto esperado en detener los impactos socio ambientales que genera esta actividad en su entorno. De ese modo, los resultados obtenidos muestran que varias de estas acciones de intervención coinciden con los años en los que se tuvo una mayor expansión del área minera explotada, y se registraron valores muy superiores al promedio. Por lo tanto, se puede concluir que la intervención del gobierno a través de normativa y actividades de control tuvo un impacto marginal y en otros nulo.

\section{REFERENCIAS}

Acosta, J., Rodríguez, I., Valencia, M. \& Flores, A. (2011). Memoria sobre la geología económica de la Región Puno. Lima: INGEMMET. Obtenido de http://www.ingemmet.gob. pe/documents/73138/468768/2011_GE33_Memoria_Geologia_Economica_Puno. pdf/84dbe665-4a0a-4b05-8ebc-d8f5c6bcbc42

Asociación SER. (2007). Conflicto en el Altiplano: Actividad Minera Informal en Ananea y Contaminación de la Cuenca del Río Ramis. Puno.

Butler, M.J.A., Mouchot, M.-C., Barale, V. \& LeBlanc, C. (1990). Aplicación de la tecnología de percepción remota a las pesquerías marinas: manual introductorio. Roma, Italia: FAO. Recuperado el 31 de agosto de 2017, de http://www.fao.org/docrep/003/ t0355s/T0355S00.HTM\#toc

Cartaya, S., Zurita, S., Rodríguez, E. \& Montalvo, V. (2015). Comprobación del NDVI en imágenes RAPIDEYE para determinar cobertura vegetal y usos de la tierra en la provincia de Manabí, Ecuador. Revista San Gregorio, 2(10,), 75-92. Recuperado de https://docs.google.com/document/d/1ZFQiVaKTMAKdwcYTF5J_yuLzMtpIBriwHeLSb5o6jhs/edit\#

Cueva Yñigo, C. (1992). Explotación de los mantos auríferos en la cordillera sur oriental del Perú. Simposium Nacional de Minería Aurifera, 2, Pasco, PE, 7-12 diciembre 1992, Trabajos técnicos, 123-131.

Diario El Peruano. (11 de agosto de 2005). Decreto Supremo Nº28-2005-EM «Suspenden admisión de petitorios en el distrito de Ananea, provincia de San Antonio de Putina, departamento de Puno y constituyen Comisión Especial». El Peruano, pág. 298347. 
DREM PUNO. (2005). Problemática ambiental por actividades mineras zona Rinconada Ananea - Chaquiminas - Pampa Blanca y Ancocala. Gobierno Regional de Puno, Puno.

El Peruano. (04 de marzo de 2012). Decreto legislativo No 1103 «Decreto legislativo que establece medidas de control y fiscalización en la distribución, transporte y comercialización de insumos químicos que puedan ser utilizados en la minería ilegal». $E l$ Peruano, pág. 461992.

Giraldo Malca, U. F. (2017). Minería informal en la cuenca alta del Ramis: impactos en el paisaje y evolución del conflicto socio ambiental. Lima: Pontificia Universidad Católica del Perú. Recuperado de http://tesis.pucp.edu.pe/repositorio/handle/123456789/1297/ browse?type $=$ author $\&$ value $=$ Giraldo + Malca $\% 2 \mathrm{C}+$ Ulises + Francisco

Glave, M. \& Kuramoto, J. (2000). Minería, Minerales y Desarrollo Sustentable en Perú. En GRADE. Lima.

La República. (25 de junio de 2011). Juliaca: Seis muertos tras violenta jornada de protesta. La República. Recuperado el 25 de agosto de 2017, de http://larepublica.pe/25-062011/juliaca-seis-muertos-tras-violenta-jornada-de-protesta

Martínez Muñoz, J. (2005). Percepción Remota «Fundamentos de teledetección espacial». México, México: Comisión Nacional del Agua. Recuperado el 31 de agosto de 2017, de http://siga.conagua.gob.mx/SIGA/Percepcion/Fundamentos\%20de $\% 20$ teledetecci\%C3\%B3n\%20espacial.PDF

Ministerio de Energía y Minas. (2016). Anuario Minero 2015. Lima: Dirección General de Minería.

Ministerio del Trabajo y Promoción del Empleo. (2015). Informe Anual del Empleo en el Perú 2014. Lima: Ministerio del Trabajo y Promoción del Empleo.

OGATEIRN-INRENA. (2006). Informe de Monitoreo al estado de los recursos naturales y contaminación ambiental en la cuenca del Ramis. Puno.

Olivari Ortega, J. (1992). Guarnacabo, mina de oro ubicada en el Collao, la primera en ser visitada por los conquistadores españoles en 1533. Revista; Simposium Nacional de Mineria Aurifera, 2, Pasco, PE7-12 diciembre 1992, Trabajos técnicos. "Dorado peruano: riqueza presente, desarrollo futuro", 341-347.

ONERN - CORPUNO. (1965). Programa de inventario y evaluación de los recursos naturales del departamento de Puno. Lima: Oficina Nacional de Evaluación de Recursos Naturales - Instituto Nacional de Planificación - Corporación de Desarrollo y Promoción Social y Económica del Departamento de Puno.

Proyecto GAMA. (2004). Propuesta Pilotaje Ananea 2004. Obtenido de Gama-Peru: http:// www.gama-peru.org/monitor/pdf/propuesta_pilotaje_ananea_2004.pdf

Vargas, J. (15 de junio de 2015). ¿Por qué es tan importante la minería para el Perú? El Comercio. Recuperado el 12 de enero de 2017, de http://elcomercio.pe/ economia/peru/importante-mineria-peru-192754 